\title{
Prevalence, Awareness, Treatment, Control, and Related Factors of Hypertension among Tajik Nomads Living in Pamirs at High Altitude
}

\author{
Lin Wang, ${ }^{1,2}$ Nanfang Li $\left(\mathbb{D},{ }^{1}\right.$ Mulalibieke Heizhati, ${ }^{1}$ Suofeiya Abulikemu, ${ }^{1}$ Delian Zhang, $^{1}$ \\ Qin Luo, ${ }^{1}$ Ling Zhou, ${ }^{1}$ Jing Hong, ${ }^{1}$ Junli Hu, ${ }^{1}$ Li Cai, ${ }^{1}$ Xin Zhao, ${ }^{1}$ Le Sun, ${ }^{1}$ and Liang Shao \\ ${ }^{1}$ Hypertension Center of People's Hospital of Xinjiang Uygur Autonomous Region, \\ Xinjiang Hypertension Institute;National Health Committee Key Laboratory of Hypertension Clinical Research Urumqi, \\ No. 91 Tianchi Road, Urumqi 830001, Xinjiang, China \\ ${ }^{2}$ Xinjiang Medical University, Urumqi, Xinjiang Uygur Autonomous Region, China
}

Correspondence should be addressed to Nanfang Li; lnanfang2016@sina.com

Received 17 January 2020; Revised 27 May 2020; Accepted 9 June 2020; Published 14 July 2020

Academic Editor: Kwok Leung Ong

Copyright $(2020$ Lin Wang et al. This is an open access article distributed under the Creative Commons Attribution License, which permits unrestricted use, distribution, and reproduction in any medium, provided the original work is properly cited.

Background. Hypertension is a global problem, for which high-altitude residents exhibit higher burden. Hypertension in Tajik nomads from Pamirs with an average altitude above $4000 \mathrm{~m}$ remains less studied. We aimed to determine the prevalence, awareness, treatment, control, and risk factors associated with hypertension among Tajik population in Pamirs. Methods. A crosssectional survey was conducted between August and September 2015 using stratified three-stage random sampling in Taxkorgan county, Pamirs, China. Hypertension is defined as mean systolic and/or diastolic blood pressure (SBP, DBP) $\geq 140 / 90 \mathrm{mmHg}$ and/ or taking antihypertensive medication within the past two weeks. The prevalence (SBP $\geq 130$ or $\mathrm{DBP} \geq 80 \mathrm{mmHg}$ ) was also estimated using the 2017 American College of Cardiology (ACC)/American Heart Association (AHA) High Blood Pressure Guideline. The awareness, treatment, and control of hypertension and associated factors were evaluated. Results. Totally, 797 subjects aged $\geq 18$ years were enrolled with $46.3 \%$ men and $88.8 \%$ nomads with the mean age of $42.3 \pm 15.2$ years. The prevalence of hypertension was $24.2 \%(140 / 90 \mathrm{mmHg})$, and the prevalence was as high as $40.3 \%$, based on the 2017 ACC/AHA guideline. Overall awareness, treatment, and control of hypertension were $52.8 \%, 40.9 \%$, and $9.3 \%$, respectively. In multivariate logistic regression, $\mathrm{BMI} \geq 24.0 \mathrm{~kg} / \mathrm{m}^{2}$ (OR: $\left.2.41,95 \% \mathrm{CI}: 1.44-4.04\right)$ was a risk factor for prehypertension, and age $\geq 60$ years (OR: $2.04,95 \%$ CI: $1.15-3.61$ ), BMI $\geq 24.0 \mathrm{~kg} / \mathrm{m}^{2}$ (OR: $2.04,95 \%$ CI: 1.15-3.61), and abdominal obesity (OR: 1.87, 95\% CI: 1.09-3.22) were risk factors for hypertension. Angiotensin-converting enzyme inhibitors/angiotensin receptor blockers were the most commonly used antihypertensive medication (45.4\%) as monotherapy, and $13.6 \%$ of treated hypertensive patients used two drugs. Conclusions. There is a considerable prevalence of hypertension with low awareness, treatment, and control rates among Tajik nomads in Pamirs, where health programs improving the hypertension status are urgently needed, with the excess weight loss as a strategy.

\section{Introduction}

Hypertension is a leading risk factor of cardiovascular disease (CVD), accounting for approximately half of the cardiovascular morbidity and mortality, which has become a serious public health problem in the world, especially in developing countries and regions due to poor management [1-3]. Residents in high-altitude regions with low temperatures and oxygen levels have indigenous diets and lifestyles (e.g., high salt diet, lack of fish, vegetables, and fruits), which can affect the development of hypertension $[4,5]$. Several studies in different high altitude areas (i.e., Latin America, USA, Europe, and Asia) show that high-altitude residents exhibit higher risk for hypertension and CVD than lowaltitude residents due to the special environment and poor medical conditions [6-8].

People living in the Andean mountains of South America, the Himalayan mountains of Tibet, and the Ethiopian summits 
of Africa are the three largest populations with the longest history of high altitude residency [9]. The status of hypertension among them has been reported in the last decades [10-12]. However, there are large differences in the magnitude of hypertension among geographic areas and ethnic groups $[13,14]$. Little attention has been devoted to determine the magnitude and management of hypertension in the Tajik population living in the Pamirs with an average altitude level of 4,500 meters. Pamirs is located in the southeastern part of Central Asia, the western part of China, and across Tajikistan and China. In addition, the main ethnic resident in Pamirs is Tajik population, who lead nomadic or seminomadic lives usually moving around with seasonal changes in order to maintain the stocks with better resource of fodders, which makes the access of fresh vegetables and fruits further difficult, penetration rate of medical resources low, and health awareness poor. All these factors have relevance with a higher prevalence of hypertension and its poor management $[15,16]$.

Numerous studies on hypertension have been carried out in China in the last few decades [17-19]. Nonetheless, studies in Pamirs are almost rare. In addition, Tajikistan is located in Northwest part of Pamirs, where the mountains and plateaus account for $90 \%$ and about half are above 3,000 meters above sea level, and therefore known as the "mountain country" [20]. The major ethnic group in Tajikistan is also the Tajiks (70\%) [20]. However, information about epidemiological investigations of hypertension of populations in Tajikistan is limited, although CVD burden is huge there as well [21].

To explore the magnitude, management, and contributors including the prescription pattern of antihypertensive agents of hypertension among Tajik population in Pamirs, our hypertension center launched an investigation in Taxkorgan county located in the eastern Pamirs with an average altitude of $4000 \mathrm{~m}$ and with Tajik population as the main ethnic group, Xinjiang, China. Thereby, the results may provide basis for the design and implementation of appropriate interventions for hypertension in Tajik residents living in Pamirs, extending to Tajikistan with the same ethnicity and approximate conditions in terms of geographical and climatic condition and hypertension-related disease burden.

\section{Materials and Methods}

2.1. Study Population. This cross-sectional study was conducted among Tajik residents in Taxkorgan county with an average altitude above $4000 \mathrm{~m}$, China, between August and September 2015. A three-stage (township-village-resident) random sampling method was used to select participants who were aged $\geq 18$ years from the general population. First, seven townships in Taxkorgan county were selected using simple random sampling (SRS). Second, two villages were selected in each townships using SRS. Finally, participants were chosen using SRS according to the population composition. Participants were chosen from the list provided by the local government registers of households. The sample size was based on a prevalence of hypertension of $40 \%$ among the population aged $\geq 18$ years from the region with an altitude of at $4000 \mathrm{~m}$ [22] and was estimated as 600 . Finally, the final sample size was calculated as $N=800$, considering as high as $25 \%$ nonresponse rate.

The eligible criteria for study population were as follows: (a) residents who live permanently in the local; (b) Tajik ethnicity; (c) residents who are willing to cooperate with the investigation (questionnaire interviews and anthropometric measurements). The exclusion criteria were as follows: (a) residents with mental diseases and without clear consciousness; (b) women who are pregnant. The study was approved by the Ethical Review Board of People's Hospital of Xinjiang Uygur Autonomous Region, China.

2.2. Training and Data Collection. All study investigators and staff members were trained to be familiar with both the aims of the study and the specific tools and methods used. A standardized questionnaire was administered by trained staff to obtain information on demographic characteristics, health-related behaviors, and hypertension-related information. Anthropometric variables were measured by trained staff after the completion of the questionnaire.

2.3. Questionnaire Interviews. Demographic characteristics (sex, age, occupation, education attainment status, personal incomes per family member, marital status, etc.), healthrelated behaviors (cigarette smoking and alcohol consumption), and hypertension-related information (whether it was previously diagnosed by a doctor? whether it has been treated? whether taking antihypertensive drugs within the previous two weeks?) were investigated by our investigators. Antihypertensive agents were recorded if they were taking them.

2.4. Measurements of Blood Pressure. Blood pressure (BP) was measured with the OMRON HBP-1300 Professional Portable Blood Pressure Monitor (OMRON, Kyoto, Japan) three times on the right arm positioned at the heart level after the participant was sitting at rest for five minutes, with 30 seconds between each measurement with an observer present. The average of the three readings was used for the analysis.

2.5. Anthropometric Variables. Anthropometric variables were measured using standard equipment and procedures including height, weight, and waist circumference (WC). Height was measured without shoes using a standard right-angle device and a fixed measurement tape (to the nearest $0.1 \mathrm{~cm}$ ). Body weight without heavy clothing was measured using an OMRON body fat and weight measurement device (V-body HBF-371, OMRON, Kyoto, Japan). WC was measured in the midpoint between the lower rib and upper margin of the iliac crest, measured by a ruler tape with an insertion buckle at one end (to the nearest $0.1 \mathrm{~cm}$ ) [23]. Body mass index (BMI) was calculated as weight divided by the square of height $\left(\mathrm{kg} / \mathrm{m}^{2}\right)$. 
2.6. Definitions. Hypertension is defined as systolic BP (SBP) $\geq 140 \mathrm{mmHg}$, and/or diastolic BP (DBP) $\geq 90 \mathrm{mmHg}$, and/or use of antihypertensive medicine within two weeks (2010 Chinese Guideline for the Management of Hypertension) [24]. The prevalence of hypertension was also estimated according to the 2017 American College of Cardiology (ACC)/American Heart Association (AHA) High Blood Pressure Guideline [25].

Prehypertension is defined as participants who have not been informed of hypertension diagnosis and with SBP 120-139 $\mathrm{mmHg}$ and/or DBP $80-89 \mathrm{mmHg}$ [24] and not on antihypertensive drugs treatment.

Awareness is defined as whether they have a medical diagnosis of hypertension and treatment as whether they are receiving BP-lowering drugs within the past two weeks. Control is defined as an average SBP and DBP $<140 /$ $90 \mathrm{mmHg}$.

Education attainment status is categorized into three levels: primary and lower, junior high and, senior high and higher. Family income per member was divided into low incomes $\leq ¥ 1500 /$ month (USA $\$ 217.4 /$ month) and high incomes $>¥ 1500 /$ month (USA $\$ 217.4 /$ month), based on Chinese individual income tax rates [26]. Marital status was coded as single, married, or widowed/divorced. Current cigarette consumption is defined as participants who have smoked at least 20 packets of cigarettes in their lifetime and currently smoke cigarettes and never smokers as participants who never smoked or smoked $<20$ packets of cigarettes in their entire lifetime [17]. Current alcohol intake is defined as consuming at least once alcoholic beverage per week in the past month [17]. Overweight and obesity are defined as a BMI between $24.0-27.9 \mathrm{~kg} / \mathrm{m}^{2}$ and of $\geq 28.0 \mathrm{~kg} / \mathrm{m}^{2}$, respectively, based on the criteria recommended by the Working Group on Obesity in China (WGOC) [24]. High BMI level $\left(\geq 24 \mathrm{~kg} / \mathrm{m}^{2}\right)$ for the current study includes overweight and obesity category. Abdominal obesity is defined as WC $\geq 90 \mathrm{~cm}$ in men and WC $\geq 85 \mathrm{~cm}$ in women [27].

Medications were classified as diuretics, beta-blockers, calcium channel blockers (CCBs), angiotensin-converting enzyme inhibitors (ACEIs), angiotensin II receptor blockers (ARBs), and traditional Chinese medicine (TCM). Except for ACEIs and ARBs, each medication was classified into only one category: participants who used $\geq 2$ class drugs as combination therapy.

\section{Statistical Analysis}

Continuous variables were presented as mean and standard deviations (SD) and analyzed using the ANOVA test. Categorical variables were expressed as frequency $(n)$ and proportion (\%) and analyzed using the chi-squared test. As for prehypertension and hypertension, multiple logistic analysis was used to analyze the associated factors, and adjusted odds ratio (OR) with associated $95 \%$ confidence interval (95\% CI) was calculated. All statistical tests were two-tailed, and differences were considered statistically significant when the $P$ value was $<0.05$. All statistical analyses were performed using SPSS 20.0 for Windows.

\section{Results}

4.1. Population Characteristics. A total of 797 Tajik subjects aged $42.30 \pm 15.21$ years were enrolled with men accounting for $46.3 \%$ (response rate 93.8\%). Characteristics of the study population are shown in Table 1. Subjects with stock-raising occupations accounted for $88.8 \%$. The education attainment status of participants was low with over two-thirds (69.1\%) having primary or lower education. Regarding the family income per member, the proportion of those with $\leq ¥ 1500 /$ month was high (73.1\%). Current smoker and current drinkers accounted for $17.4 \%$ and $8.6 \%$, respectively. The overall prevalence of overweight and obesity (BMI $\geq 24.0 \mathrm{~kg} / \mathrm{m}^{2}$ ) and abdominal obesity were $54.1 \%$ and $45.9 \%$, respectively.

4.2. Level of Blood Pressure by Age and Sex. Figures 1(a) and 1(b) show the mean BP of all participants by age and sex. Mean SBP and DBP of the participants were $(125.7 \pm 20.3)$ $\mathrm{mmHg}$ and $(74.2 \pm 11.5) \mathrm{mmHg}$, respectively (Supplementary Table 1). SBP and DBP increased significantly with age $(P<0.05)$, while DBP did not show this trend in men.

4.3. Prevalence of Prehypertension and Hypertension. The overall prevalence of prehypertension and hypertension was $30.1 \%$ (95\% CI, 26.8\%-33.5\%) and 24.2\% (95\% CI, $21.2 \%-$ $27.3 \%$ ), respectively, as shown in Table 2 . The prevalence of hypertension, based on the 2017 ACC/AHA guideline, was approximately twice as high as that based on 2010 Chinese guideline ( $40.3 \%$ vs $24.2 \%$ ). The prevalence of hypertension increased significantly with the advanced age $(P$ values for trend $=0.002)$, while this trend was not observed in the prevalence of prehypertension $(P=0.894)$. The prevalence of prehypertension and hypertension showed no significant differences between men and women, as well as between different family income per member groups $(P>0.05)$. The prevalence of hypertension was higher in participants with low education attainment $(P=0.006)$, divorced status $(P=0.003)$, and $\mathrm{BMI} \geq 24.0 \mathrm{~kg} / \mathrm{m}^{2}(P<0.001)$.

4.4. Awareness, Treatment, and Control of Hypertension. Among those with hypertension, 52.8\% (95\% CI, 45.7\%$59.9 \%$ ) were aware of their condition, $40.9 \%$ (95\% CI, 33.9\%47.9\%) were taking antihypertensive agents, whereas only $9.3 \%$ (95\% CI, 5.2\%-13.6\%) achieved BP control, and control rate among treated hypertensives was $22.7 \%$ (95\% CI, $15.1 \%-$ 30.3\%) in Table 3.

The awareness and treatment of hypertension significantly increased with age (both $P$ values for trend $<0.01$ ). Though not reaching statistical significance, the awareness, treatment, and control of hypertension were lower among population with low family incomes than their counterparts (51.8\% vs. $56.5 \%, 36.9 \%$ vs. $44.3 \%, 6.6 \%$ vs. $11.1 \%$, all $P$ values $>0.05$ ), and the awareness of hypertension was lower in population with single marital status than married and divorce status ( $25.0 \%$ vs. $51.9 \%, 68.9 \%$, $P$ value $=0.033$ ). There were no significant differences in the awareness, treatment, and control of hypertension between genders (all $P$ values $>0.05$ ). 
TABLE 1: Baseline characteristics of the study population by sex.

\begin{tabular}{|c|c|c|c|c|}
\hline Variables & Men $(n=369)$ & Women $(n=428)$ & Total $(n=797)$ & $P$ \\
\hline Age (years) & $42.19 \pm 15.21$ & $42.40 \pm 15.23$ & $42.30 \pm 15.21$ & 0.849 \\
\hline $18-44$ & $224(60.7)$ & $254(59.3)$ & $478(60.0)$ & \\
\hline $45-59$ & $93(25.2)$ & $115(26.9)$ & $208(26.1)$ & 0.867 \\
\hline$\geq 60$ & $52(14.1)$ & $59(13.8)$ & $111(13.9)$ & \\
\hline Stock raisers $(n, \%)$ & $325(88.1)$ & $383(89.5)$ & $708(88.8)$ & 0.601 \\
\hline \multicolumn{5}{|l|}{ Education attainment status $(n, \%)$} \\
\hline Primary and lower & $215(58.4)$ & $336(78.3)$ & $551(69.1)$ & \multirow{3}{*}{$<0.001$} \\
\hline Junior high & $78(21.2)$ & $66(15.4)$ & $144(18.1)$ & \\
\hline Senior high and higher & $75(20.4)$ & $27(6.3)$ & $102(12.8)$ & \\
\hline Family income per member $(n, \%)$ & & & & 0.001 \\
\hline Low & $247(66.9)$ & $336(78.5)$ & $583(73.1)$ & \\
\hline High & $122(33.1)$ & $92(21.5)$ & $214(26.9)$ & $<0.001$ \\
\hline \multicolumn{5}{|l|}{ Marital status $(n, \%)$} \\
\hline Single & $48(13.0)$ & $28(6.5)$ & $76(9.5)$ & \multirow[t]{3}{*}{$<0.001$} \\
\hline Married & $298(80.8)$ & $348(81.3)$ & $646(81.1)$ & \\
\hline Widowed/divorced & $23(6.2)$ & $52(12.2)$ & $75(9.4)$ & \\
\hline Current cigarette consumption $(n, \%)$ & $137(37.1)$ & $2(0.5)$ & $139(17.4)$ & $<0.001$ \\
\hline Current alcohol intake $(n, \%)$ & $69(18.7)$ & $0(0)$ & $69(8.6)$ & - \\
\hline \multicolumn{5}{|l|}{ Body mass index } \\
\hline$<23.9 \mathrm{~kg} / \mathrm{m}^{2}$ & $173(46.9)$ & $193(45.1)$ & $366(45.9)$ & \multirow{2}{*}{0.619} \\
\hline$\geq 24.0 \mathrm{~kg} / \mathrm{m}^{2}$ & $196(53.1)$ & $235(54.9)$ & $431(54.1)$ & \\
\hline \multicolumn{5}{|l|}{ Waist circumference } \\
\hline Abdominal obesity $(n, \%)$ & $135(36.6)$ & $200(46.7)$ & $335(42.0)$ & 0.003 \\
\hline
\end{tabular}

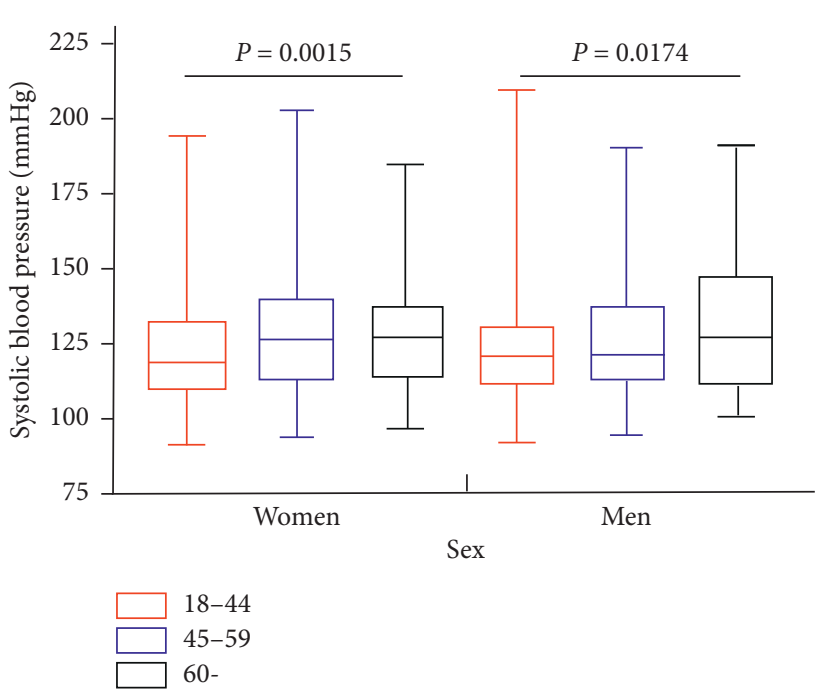

(a)

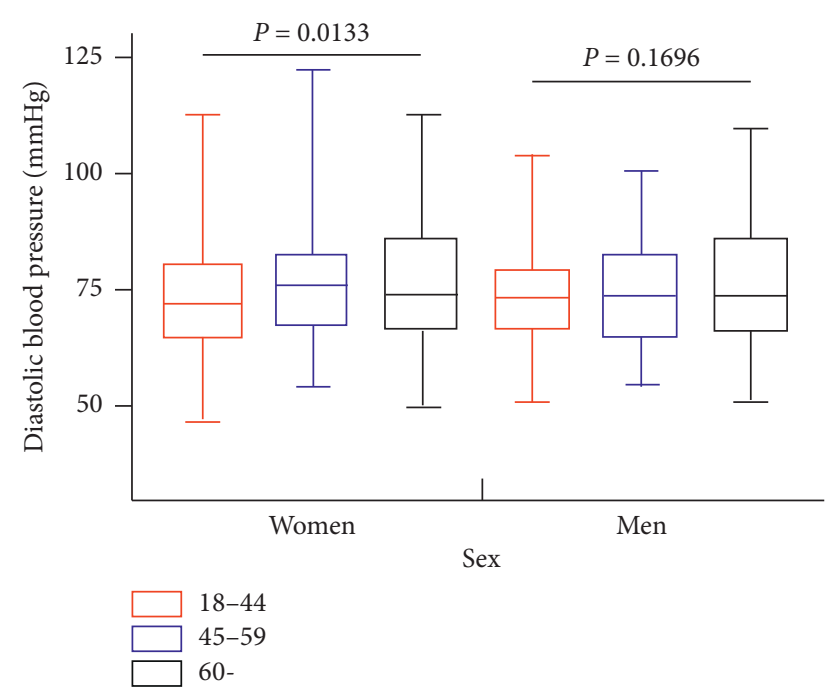

(b)

FIgURE 1: Level of blood pressure by age and sex (a) for systolic blood pressure and (b) for diastolic blood pressure.

4.5. Multivariable Risk Assessment. Tables 4 and 5 show the results of multiple logistic regression analysis of associations of potential risk factors with prehypertension and hypertension among participants, respectively. Higher BMI (OR: 2.41, 95\% CI: 1.44-4.04) could increase prevalence of prehypertension. Age $\geq 60$ years (OR: 2.04, 95\% CI: $1.15-3.61$ ), BMI $\geq 24.0 \mathrm{~kg} / \mathrm{m}^{2}$ (OR: 2.04, 95\% CI: 1.15-3.61), and abdominal obesity (OR: 1.87, 95\% CI: 1.09-3.22) were significantly associated with the presence of hypertension.
4.6. Pattern of Antihypertensive Agent Usage. A total of 74 hypertensive individuals were reported taking antihypertensive drugs at the time of the survey, whereas $59.5 \%$ $(n=44)$ of the subjects provided the detailed information on drug use (Table 6), of whom, $45.4 \%$ were taking ACEI/ARBs, $31.8 \%$ taking CCBs, $11.3 \%$ beta blockers, $11.3 \%$ diuretics, and $13.6 \%$ TCM. While further analyzing the combination therapy, it was observed that $13.6 \%$ of hypertensive individuals were prescribed for two classes drugs and no patients prescribed for three or more drugs. 
TABLe 2: Prevalence of prehypertension and hypertension in the study population.

\begin{tabular}{|c|c|c|c|}
\hline Stratification & PHT $(n=240)(\%)(95 \% \mathrm{CI})$ & $\mathrm{HT}^{1}(n=193)(\%)(95 \% \mathrm{CI})$ & $\mathrm{HT}^{2}(n=321)(\%)(95 \% \mathrm{CI})$ \\
\hline \multicolumn{4}{|l|}{ Sex } \\
\hline Men & $30.1(25.6-34.9)$ & $23.6(19.5-28.2)$ & $39.1(34.5-43.8)$ \\
\hline Women & $30.1(26.2-34.7)$ & $24.8(20.8-29.0)$ & $40.8(35.1-46.2)$ \\
\hline$P$ value & 1.000 & 0.740 & 0.613 \\
\hline \multicolumn{4}{|l|}{ Age } \\
\hline $18-44$ & $29.9(25.6-34.3)$ & $20.1(16.7-23.9)$ & $33.3(23.9-33.9)$ \\
\hline $45-59$ & $31.2(25.3-37.9)$ & $28.4(22.6-38.9)$ & $49.0(41.2-51.7)$ \\
\hline$\geq 60$ & $28.8(21.1-37.9)$ & $34.2(25.9-43.6)$ & $54.1(50.1-61.6)$ \\
\hline$P$ value & 0.894 & 0.002 & $<0.001$ \\
\hline \multicolumn{4}{|l|}{ Education attainment status } \\
\hline Primary and lower & $28.7(24.6-32.7)$ & $26.5(22.9-30.3)$ & $42.1(37.1-47.0)$ \\
\hline Junior high & $35.4(28.0-43.6)$ & $22.9(16.7-30.5)$ & $39.9(34.3-45.2)$ \\
\hline Senior high and higher & $30.4(22.2-40.0)$ & $13.7(8.2-21.9)$ & $28.8(23.1-34.3)$ \\
\hline$P$ value & 0.297 & 0.006 & 0.017 \\
\hline \multicolumn{4}{|l|}{ Family income per member } \\
\hline Low (reference) & $30.5(25.6-35.3)$ & $23.8(18.0-29.5)$ & $41.1(35.4-46.2)$ \\
\hline High & $28.9(24.8-33.1)$ & $25.2(18.2-32.3)$ & $39.2(34.7-45.9)$ \\
\hline$P$ value & 0.764 & 0.602 & 0.926 \\
\hline \multicolumn{4}{|l|}{ Marital status } \\
\hline Single (reference) & $36.8(26.7-48.3)$ & $15.8(9.1-25.8)$ & $31.2(25.6-36.8)$ \\
\hline Married & $28.9(25.1-32.8)$ & $23.5(20.3-26.9)$ & $38.5(33.5-43.7)$ \\
\hline Divorced & $33.3(23.6-44.8)$ & $38.7(28.3-50.2)$ & $63.2(56.2-70.1)$ \\
\hline$P$ value & 0.291 & 0.003 & $<0.001$ \\
\hline \multicolumn{4}{|l|}{ Body mass index } \\
\hline$<23.9 \mathrm{~kg} / \mathrm{m}^{2}$ (reference) & $19.4(15.3-23.5)$ & $13.7(10.1-17.2)$ & $22.1(17.8-26.4)$ \\
\hline$\geq 24.0 \mathrm{~kg} / \mathrm{m}^{2}$ & $39.2(34.6-43.8)$ & $33.2(28.7-37.6)$ & $55.7(50.9-60.4)$ \\
\hline$P$ value & $<0.001$ & $<0.001$ & $<0.001$ \\
\hline Overall & $30.1(26.8-33.5)$ & $24.2(21.2-27.3)$ & $40.3(36.1-44.1)$ \\
\hline
\end{tabular}

PHT, prehypertension; HT, hypertension; CI, confidence intervals. ${ }^{1}$ Based on the criteria of 2010 Chinese High Blood Pressure Guideline. ${ }^{2}$ Based on the criteria of 2017 ACC/AHA High Blood Pressure Guideline.

\section{Discussion}

This survey is the first in Tajik population living in Pamirs with an altitude of at least $4000 \mathrm{~m}$ China to report the hypertension status in relatively representative population aged $\geq 18$ years including nearly $90 \%$ stock raisers. The prevalence of hypertension is $24.2 \%$, with poor awareness, treatment, and control rates. A minority of hypertensive individuals is treated, and less than 1 in 10 hypertensives have their BP controlled. In addition, control rate of hypertension among treated individuals is less than one quarter. Less than one-seventh receives two or more drugs at the time of survey.

Some studies on hypertension in high-altitude residents have been carried out in the last few decades [10-12]. The prevalence of hypertension at different high altitude locations ranges from $8.6 \%$ to $55.9 \%[28,29]$. A meta-analysis synthesizing high altitude prevalence studies suggests an altitude gradient in the prevalence of hypertension. That is, the prevalence increases with increasing altitude [22]. In addition, the prevalence of hypertension is $44.6 \%$ and $41.4 \%$ in Tibetan and non-Tibetan populations living at altitude of $\geq 4000 \mathrm{~m}$, respectively [22]. Nonetheless, the prevalence is $24.2 \%$ in Tajik residents in the Pamirs plateau at an altitude of $\geq 4,000 \mathrm{~m}$. The current study is unable to explain the inconsistency in the prevalence, whereas it is possibly related to following factors. First, the Tajik people may have a better adaptation to the high-altitude hypoxic environment, in terms of genetic susceptibility of the population and adaptability to high-altitude hypoxia $[9,30,31]$, which may imply that ethnic and regional differences may cause diversity in the prevalence of hypertension. However, further studies on interaction mechanism of hypertension between the genetic and environmental and strength of the relationships are warranted on this aspect. Second, the minimum age to participate in the present study was 18 years, whereas other studies usually included participants from the age of 40 years or over [29,32]. Nonetheless, hypertension increases in prevalence with the age.

The current study shows different results compared with studies including the same age groups at other high altitudes. For instance, a recent survey of hypertension and diabetes mellitus conducted in Uttarakhand, India (altitude of $2084 \mathrm{~m}$ ), found that $54.5 \%$ of participants aged $\geq 60$ years have hypertension [10]. This contrasts with our study's $34.2 \%$ prevalence of hypertension. Divergent results may partly be explained by characteristics of researches, including differences in region, ethnicity, lifestyle, and sampling methodology. For instance, participants in our survey are randomly selected, with selection bias less than that conducted in door-to-door-based study in Uttarakhand. When the door-to-door method is used to select the samples, persons who stay at home due to chronic diseases are more likely to be selected, which may increase the prevalence of 
TABLE 3: Awareness, treatment, and control of hypertension in the study population.

\begin{tabular}{|c|c|c|c|c|}
\hline & $\begin{array}{c}\text { Awareness }(n=102)(\%) \\
(95 \% \mathrm{CI})\end{array}$ & $\begin{array}{c}\text { Treatment }(n=79)(\%) \\
(95 \% \mathrm{CI})\end{array}$ & $\begin{array}{c}\text { Control }(n=18)(\%) \\
(95 \% \mathrm{CI})\end{array}$ & $\begin{array}{l}\text { Control in the treated }(n=18)(\%) \\
(95 \% \mathrm{CI})\end{array}$ \\
\hline \multicolumn{5}{|l|}{ Sex } \\
\hline Men & $50.6(39.8-61.2)$ & $41.3(30.8-51.9)$ & $9.2(3.0-15.4)$ & $22.3(13.7-31.0)$ \\
\hline Women & $54.7(45.1-64.3)$ & $40.5(31.1-50.1)$ & $9.4(3.8-15.1)$ & $23.2(9.5-37.2)$ \\
\hline$P$ value & 0.664 & 0.909 & 0.995 & 0.913 \\
\hline \multicolumn{5}{|l|}{ Age } \\
\hline $18-44$ & $35.4(25.7-45.2)$ & $29.2(19.9-38.4)$ & $6.2(1.3-11.1)$ & $21.2(9.5-32.8)$ \\
\hline $45-59$ & $64.4(51.8-76.9)$ & $54.2(41.1-67.3)$ & $10.2(2.2-18.1)$ & $18.8(5.2-32.4)$ \\
\hline$\geq 60$ & $78.9(65.4-92.5)$ & $50.0(33.3-66.7)$ & $15.8(3.6-27.9)$ & $31.6(22.6-40.5)$ \\
\hline$P$ value & $<0.001$ & 0.004 & 0.223 & 0.560 \\
\hline \multicolumn{5}{|c|}{ Education attainment status } \\
\hline $\begin{array}{l}\text { Primary and } \\
\text { lower }\end{array}$ & $56.4(48.7-64.1)$ & $41.7(33.9-49.8)$ & $10.7(5.8-15.6)$ & $25.6(14.3-36.8)$ \\
\hline Junior high & $39.4(21.7-56.1)$ & $33.3(16.2-50.6)$ & $5.9(2.5-9.3)$ & $17.7(8.4-27.1)$ \\
\hline $\begin{array}{l}\text { Senior high and } \\
\text { higher }\end{array}$ & $50.0(20.0-79.9)$ & $50.0(38.2-61.7)$ & $6.2(1.5-10.9)$ & $12.4(2.9-21.8)$ \\
\hline$P$ value & 0.214 & 0.520 & 0.314 & 0.271 \\
\hline \multicolumn{5}{|c|}{ Family income per member } \\
\hline Low & $51.8(41.9-60.8)$ & $36.9(27.8-46.1)$ & $6.6(1.3-11.9)$ & $17.9(7.6-28.1)$ \\
\hline High & $56.5(40.4-70.6)$ & $44.3(29.3-59.5)$ & $11.1(1.5-20.5)$ & $25.1(13.2-37.1)$ \\
\hline$P$ value & 0.724 & 0.469 & 0.778 & 0.879 \\
\hline \multicolumn{5}{|l|}{ Marital status } \\
\hline Single & $25.0(3.7-46.3)$ & $21.0(3.4-38.7)$ & - & - \\
\hline Married & $51.9(43.6-59.3)$ & $42.1(34.1-50.0)$ & $9.2(2.6-15.5)$ & $21.8(11.9-31.6)$ \\
\hline Divorced & $68.9(51.0-86.8)$ & $41.3(22.3-60.4)$ & $10.0(2.9-17.1)$ & $24.2(4.2-44.1)$ \\
\hline$P$ value & 0.033 & 0.509 & 0.516 & 0.627 \\
\hline \multicolumn{5}{|l|}{ Body mass index } \\
\hline$<23.9 \mathrm{~kg} / \mathrm{m}^{2}$ & $48.0(33.6-62.3)$ & $32.0(18.6-45.4)$ & $12.0(2.6-21.3)$ & $37.5(24.5-50.6)$ \\
\hline$\geq 24.0 \mathrm{~kg} / \mathrm{m}^{2}$ & $54.5(46.3-62.8)$ & $44.1(35.8-52.3)$ & $8.4(3.7-12.9)$ & $19.0(4.4-33.6)$ \\
\hline$P$ value & 0.511 & 0.181 & 0.572 & 0.179 \\
\hline Overall & $52.8(45.7-59.9)$ & 40.9 (33.9-47.9) & $9.3(5.2-13.6)$ & $22.7(15.1-30.3)$ \\
\hline
\end{tabular}

Control is defined as BP $<140 / 90 \mathrm{mmHg}$; CI, confidence intervals.

hypertension in the entire study. Moreover, Uttarakhand is mainly occupied Brahmin and Kshatriya populations [33], mainly from east Eurasia [34] and may have different genetic background, compared with Tajiks. Therefore, different ethnicity can also have a role on the prevalence of hypertension $[35,36]$.

The current study contains some information compared with the national hypertension survey. The prevalence of hypertension in Tajik nomads living in Pamirs with altitude of $\geq 4000$ meter is similar to the national prevalence of China for the population aged $\geq 18$ years (23.2\%) [17]. Additionally, the average SBP and DBP levels of the sampled population are consistent with the national average. This may be because long-term residents of high altitude do not seem to differ from others in resting BP in non-Tibetans [22]. Furthermore, in the present study, only $17.4 \%$ and $8.6 \%$ of the participants self-reported to be current smokers and drinkers, respectively, which is less than the national prevalence of $20.6 \%$ and $15.8 \%$ for the Chinese population aged $\geq 18$ years [17]. As a result, the influence of the altitude may have been obscured by lifestyle-related risk changes. Nevertheless, in the present study, the control of hypertension was very poor, compared with the national control rate $(9.3 \%$ vs. $15.3 \%)$. Background possible reasons may include the following. First, medications are not readily available in stock-raising regions [37], and larger proportions of stock raisers could not afford the drugs [38, 39]. Furthermore, hypertensives stop taking agents when BP is controlled, resulting in uncontrolled BP when checked later [40]. Second, agent selection at high-altitude regions has impacts on BP control as well. For instance, BP-lowering efficacy of ARBs is poor reportedly at higher altitude [41]. Nonetheless, ARB/ACEI accounts for $45.4 \%$ in current treated subjects. Moreover, prescription patterns of village care-providers are different from those of tertiary hospital physicians [40]. In fact, only $13.6 \%$ of hypertensives in the survey received combination therapy, possibly standing for one of the reasons for poorly managed hypertension here.

Therefore, our findings highlight the need for developing a region-targeted hypertension education program to coordinate the efforts of detection, prevention, and treatment of hypertension in plateau regions. In addition, considering the limited availability of antihypertensive drugs and the limited affordability of locals, especially of nomads, exploring and promoting simplified, easy-to-master and costeffective antihypertensive algorithms might be the good pathway for hypertension control.

BMI and body weight are the best predictors of higher $\mathrm{BP}$ in high altitude residents [22]. This is consistent with current results that the correlation with prehypertension and 
TABLE 4: Factors associated with prehypertension from study population by multiple logistic regression.

\begin{tabular}{|c|c|c|c|}
\hline Stratification & $N(\%)$ & $\begin{array}{l}\text { PHT OR } \\
(95 \% \text { CI })\end{array}$ & $P$ value \\
\hline \multicolumn{4}{|l|}{$\begin{array}{l}\text { Sex } \\
\text { Sex }\end{array}$} \\
\hline Men & $\begin{array}{c}111 / 369 \\
(30.1)\end{array}$ & 1 (reference) & \multirow{2}{*}{0.458} \\
\hline Women & $\begin{array}{c}129 / 428 \\
(30.1)\end{array}$ & $\begin{array}{c}1.19 \\
(0.76-1.87)\end{array}$ & \\
\hline \multicolumn{4}{|l|}{ Age } \\
\hline $18-44$ & $\begin{array}{c}143 / \\
478(29.9)\end{array}$ & 1 (reference) & \\
\hline $45-59$ & $65 / 208(31.2)$ & $\begin{array}{c}0.92 \\
(0.60-1.40)\end{array}$ & 0.687 \\
\hline$\geq 60$ & $32 / 111(28.8)$ & $\begin{array}{c}0.65 \\
(0.35-1.19)\end{array}$ & 0.160 \\
\hline \multicolumn{4}{|c|}{ Education attainment status } \\
\hline Primary and lower & $\begin{array}{c}158 / 551 \\
(28.7)\end{array}$ & 1 (reference) & \\
\hline Junior high & $51 / 144(35.4)$ & $\begin{array}{c}1.49 \\
(0.91-2.45)\end{array}$ & 0.113 \\
\hline $\begin{array}{l}\text { Senior high and } \\
\text { higher }\end{array}$ & $31 / 102(30.4)$ & $\begin{array}{c}1.19 \\
(0.68-2.09)\end{array}$ & 0.532 \\
\hline \multicolumn{4}{|c|}{ Family income per member } \\
\hline Low & $\begin{array}{c}178 / 583 \\
(30.5)\end{array}$ & 1 (reference) & \multirow{2}{*}{0.540} \\
\hline High & $62 / 214(28.9)$ & $\begin{array}{c}0.88 \\
(0.58-1.34)\end{array}$ & \\
\hline \multicolumn{4}{|l|}{ Marital status } \\
\hline Single & $28 / 76(36.8)$ & 1 (reference) & \multirow[b]{2}{*}{0.897} \\
\hline Married & $\begin{array}{c}187 / 646 \\
(28.9)\end{array}$ & $\begin{array}{c}1.05 \\
(0.52-2.10)\end{array}$ & \\
\hline Divorced & $25 / 75(33.3)$ & $\begin{array}{c}1.14 \\
(0.43-3.01)\end{array}$ & 0.798 \\
\hline \multicolumn{4}{|l|}{ Body mass index } \\
\hline BMI: $<23.9 \mathrm{~kg} / \mathrm{m}^{2}$ & $71 / 366(19.4)$ & 1 (reference) & \multirow[b]{2}{*}{$<0.001$} \\
\hline BMI: $\geq 24.0 \mathrm{~kg} / \mathrm{m}^{2}$ & $\begin{array}{c}169 / 431 \\
(39.2)\end{array}$ & $\begin{array}{c}2.41 \\
(1.44-4.04)\end{array}$ & \\
\hline \multicolumn{4}{|c|}{ Waistline circumference } \\
\hline Normal & $\begin{array}{c}111 / 462 \\
(24.0)\end{array}$ & 1 (reference) & \multirow{2}{*}{0.319} \\
\hline Abdominal obesity & $\begin{array}{c}129 / 335 \\
(38.5)\end{array}$ & $\begin{array}{c}1.29 \\
(0.78-2.12)\end{array}$ & \\
\hline \multicolumn{4}{|c|}{ Current cigarette consumption } \\
\hline No & $\begin{array}{c}198 / 658 \\
(30.1)\end{array}$ & 1 (reference) & \multirow{2}{*}{0.420} \\
\hline Yes & $42 / 139(30.2)$ & $\begin{array}{c}1.25 \\
(0.73-2.13)\end{array}$ & \\
\hline \multicolumn{4}{|l|}{ Current alcohol intake } \\
\hline No & $\begin{array}{c}215 / 728 \\
(29.5)\end{array}$ & 1 (reference) & \multirow{2}{*}{0.156} \\
\hline Yes & $25 / 69(36.2)$ & $\begin{array}{c}1.56 \\
(0.84-2.90) \\
\end{array}$ & \\
\hline
\end{tabular}

Adjusted factors include all above variables. PHT, prehypertension; OR: odd ratio; CI: confidence interval.

hypertension is higher among overweight and obese subjects than others. The mechanism by which obesity is linked with hypertension is not properly understood. However, an increase in insulin resistance, sympathetic activity, hyperleptinemia, renal abnormalities, and sodium retention is thought to be the likely underlying pathway [42]. Therefore,
TABLE 5: Factors associated with hypertension from study population by multiple logistic regression.

\begin{tabular}{|c|c|c|c|}
\hline Stratification & $N(\%)$ & $\begin{array}{l}\text { HT OR } \\
(95 \% \mathrm{CI})\end{array}$ & $\begin{array}{c}P \\
\text { value }\end{array}$ \\
\hline \multicolumn{4}{|l|}{ Sex } \\
\hline Men & $87 / 369(23.6)$ & 1 (reference) & \multirow[b]{2}{*}{0.281} \\
\hline Women & $\begin{array}{c}106 / 428 \\
(24.8)\end{array}$ & $0.77(0.48-1.24)$ & \\
\hline \multicolumn{4}{|l|}{ Age } \\
\hline $18-44$ & $96 / 478(20.1)$ & 1 (reference) & \\
\hline $45-59$ & $59 / 208(28.4)$ & $1.53(0.97-2.40)$ & 0.067 \\
\hline$\geq 60$ & $38 / 111(34.2)$ & $2.04(1.15-3.61)$ & 0.015 \\
\hline \multicolumn{4}{|c|}{ Education attainment status } \\
\hline Primary and lower & $\begin{array}{c}146 / \\
551(26.5)\end{array}$ & 1 (reference) & \\
\hline Junior high & $33 / 144(22.9)$ & $0.87(0.50-1.52)$ & 0.633 \\
\hline $\begin{array}{l}\text { Senior high and } \\
\text { higher }\end{array}$ & $14 / 102(13.7)$ & $0.43(0.22-0.87)$ & 0.019 \\
\hline
\end{tabular}

Family income per member

$\begin{array}{ccc}\text { Low } & 139 / & 1 \text { (reference) } \\ \text { High } & 583(23.8) & \\ \text { Haris } & 54 / 214(25.2) & 1.21(0.78-1.88)\end{array}$

0.399

Marital status Single

Married

Divorced

$12 / 76(15.8) \quad 1$ (reference) $152 / 646-0.91(0.40-2.12)$ $\begin{array}{lll}(23.5) & 0.91(0.40-2.12) & 0.834\end{array}$

Body mass index BMI: $<23.9 \mathrm{~kg} / \mathrm{m}^{2}$ $29 / 75(38.7) \quad 1.72(0.60-4.96) \quad 0.313$

BMI: $\geq 24.0 \mathrm{~kg} / \mathrm{m}^{2}$

50/366 (13.7) 1 (reference) $143 / 431 \quad 2.04(1.15-3.61) \quad 0.014$

Waistline circumference Normal 68/462 (14.7) 1 (reference) Abdominal obesity $125 / 335 \quad 1.87(1.09-3.22)$ 0.023

Current cigarette consumption

$\begin{array}{lccc}\text { No } & 157 / 658 & 1 \text { (reference) } & 0.432 \\ & (23.8) & & \\ \text { Yes } & 36 / 139(25.9) & 1.27(0.70-2.31) & \\ \text { Current alcohol intake } & & & \\ \text { No } & 174 / 728 & 1 \text { (reference) } & 0.284 \\ \text { Yes } & (23.9) & & \end{array}$

Adjusted factors include all above variables; HT, hypertension; OR: odds ratio; CI: confidence interval; the diagnosis of hypertension is based on the criteria of 2010 Chinese High Blood Pressure Guideline.

control of BMI is a critical public health priority in prevention of hypertension locally as well.

The Tajik residents mainly live in the Pamirs and are distributed in Taxkorgan county, Xinjiang, China, and Tajikistan, who still share life style and geographical and climatic environment and burden of CVD including hypertension. Therefore, results of the current study could extend to Tajik population from Tajikistan population living in a similar altitude and nearby areas in terms of prevention of hypertension.

\section{Strengths and limitations}

Current analysis is strengthened by relatively representative study subjects from the Tajik ethnic group, which makes the 
TABle 6: Use of antihypertensive medications in the treated hypertensives.

\begin{tabular}{lcc}
\hline Type of antihypertensive drug & $N$ & $(\%)$ \\
\hline ACEI/ARBs & 20 & 45.4 \\
CCBs & 14 & 31.8 \\
Beta blockers & 5 & 11.3 \\
Diuretics & 5 & 11.3 \\
TCM & 6 & 13.6 \\
Two classes & 6 & 13.6 \\
\hline
\end{tabular}

ACEI, angiotensin-converting enzyme inhibitors. ARB, angiotensin receptor blockers. CCB, calcium channel blockers. TCM, traditional Chinese medicine.

report one of the valuable information for public health sectors and for clinical setting. However, this study contains some limitations. First of all, the cross-sectional nature of the study does not allow to get a cause-and-effect relationship between hypertension and related factors. However, it is also the common way of finding problems and providing clues for prevention. Second, current analysis failed to focus on the data of salt intake, blood lipid, and glucose, which might have brought some bias on analysis of associated factors of prehypertension and hypertension. However, their relationship with hypertension is well-established and still the focus when providing individualized treatment or in population level programs. Third, this study had a relatively small sample size, which may have diminished the statistical power for subgroup analysis. Fourth, we tried to provide information on the drug use pattern here, whereas approximately $40 \%$ of hypertensive subjects lacked of data on this aspect, which may have had some information bias. This observation needs further confirmation in studies with well-powered sample size.

\section{Conclusions}

Prevalence of hypertension is considerable among Tajik nomads aged $\geq 18$ years living in Pamirs with an altitude of $\geq 4000 \mathrm{~m}$, China with poor awareness, treatment and control rates. Excess weight loss is a vital strategy for prevention of hypertension. In addition, improving the access of primary care, strengthening the ability construction of medical teams and exploring optimized anti-hypertensive algorithms are crucial to improve the hypertension status in the stockraising region of Pamirs. Current results could also extend to Tajik population from Tajikistan population living similar altitude and nearby areas.

\section{Data Availability}

Materials included in the manuscript, excluding the relevant raw data, will be made freely available to any researchers who wish to use them for noncommercial purposes, while preserving any necessary confidentiality and anonymity.

\section{Ethical Approval}

Ethics approval was obtained from the Ethics Review Committee of People's Hospital of Xinjiang Uygur Autonomous Region.

\section{Conflicts of Interest}

The authors declare that they have no conflicts of interest.

\section{Authors' Contributions}

LW, NL, and MH contributed equally to this work. NL was involved in the study design. NL, LW, MH, SA, DZ, QL, LZ, $\mathrm{JH}, \mathrm{JH}, \mathrm{LC}, \mathrm{XZ}, \mathrm{LS}$, and LS collected the data. LW performed the statistical analysis. LW drafted the manuscript. $\mathrm{MH}$ critically revised the manuscript. NL, SA, DZ, QL, LZ, JH, and $\mathrm{JH}$ gave important suggestions and did significant changes. All authors reviewed and approved the final version of the paper.

\section{Acknowledgments}

This work was supported by a grant from the Department of Science and Technology of Xinjiang Uygur Autonomous Region of China (2017B03015). The authors thank all the individuals who participated in the present study. The authors thank the Ministry of Science and Technology of the People's Republic of China and the Department of Science and Technology of Xinjiang Uygur Autonomous Region of China for funding the project. The authors thank nurse Riziwangu Abudu for collecting blood samples from participants in this study.

\section{Supplementary Materials}

Supplementary Table 1: mean systolic and diastolic blood pressure by age and sex. (Supplementary Materials)

\section{References}

[1] J. He, D. Gu, J. Chen et al., "Premature deaths attributable to blood pressure in China: a prospective cohort study," The Lancet, vol. 374, no. 9703, pp. 1765-1772, 2009.

[2] GBD Causes of Death Collaborators, "Global, regional, and national age-sex specific mortality for 264 causes of death, 1980-2016: a systematic analysis for the global burden of disease study," The Lancet, vol. 390, no. 10100, pp. 1151-1210, 2017.

[3] C. M. Lawes, S. V. Hoorn, and A. Rodgers, "Global burden of blood-pressure-related disease, 2001," The Lancet, vol. 371, no. 9623, pp. 1513-1518, 2008.

[4] D. Vinnikov, N. Brimkulov, and V. Krasotski, "Chronic intermittent hypoxia and blood pressure: is there risk for hypertension in healthy individuals?" High Altitude Medicine \& Biology, vol. 17, no. 1, pp. 5-10, 2016.

[5] D. Chiang, H. Kramer, A. Luke et al., "25-hydroxyvitamin D and blood pressure," Journal of Hypertension, vol. 35, no. 5, pp. 968-974, 2017.

[6] K. H.- Enriquez and O. N.- Guerra, "Discordance of metabolic syndrome and abdominal obesity prevalence according to different criteria in andean highlanders: a community-based study," Diabetes \& Metabolic Syndrome, vol. 11, pp. 359-364, 2017.

[7] F. Lindgärde, M. B. Ercilla, L. R. Correa, and B. Ahrén, "Body adiposity, insulin, and leptin in subgroups of peruvian amerindians," High Altitude Medicine \& Biology, vol. 5, no. 1, pp. 27-31, 2004. 
[8] S. Tyrovolas, C. Chalkias, M. Morena et al., "Health care access and prevalence of the metabolic syndrome among elders living in high-altitude areas of the Mediterranean islands: the MEDIS study," The Review of Diabetic Studies, vol. 8, no. 4, pp. 468-476, 2011.

[9] C. M. Beall, "Two routes to functional adaptation: tibetan and andean high-altitude natives," Proceedings of the National Academy of Sciences, vol. 104, no. Supplement 1, pp. 86558660, 2007.

[10] U. Kapil, R. Khandelwal, L. Ramakrishnan et al., "Prevalence of hypertension, diabetes, and associated risk factors among geriatric population living in a high-altitude region of rural Uttarakhand, India," Journal of Family Medicine and Primary Care, vol. 7, no. 6, pp. 1527-1536, 2018.

[11] P. C. Negi, R. Bhardwaj, A. Kandoria et al., "Epidemiological study of hypertension in natives of Spiti Valley in Himalayas and impact of hypobaric hypoxemia; a cross-sectional study," The Journal of the Association of Physicians of India, vol. 60, pp. 21-25, 2012.

[12] X. Zheng, D. K. Yao, C. R. Zhuo-Ma et al., "Prevalence, selfawareness, treatment, and control of hypertension in Lhasa, Tibet," Clinical and experimental hypertension, vol. 34, no. 5, pp. 328-333, 2012.

[13] Y. Li, L. Wang, X. Feng et al., "Geographical variations in hypertension prevalence, awareness, treatment and control in China," Journal of Hypertension, vol. 36, no. 1, pp. 178-187, 2018.

[14] N. Li, H. Wang, Z. Yan, X. Yao, J. Hong, and L. Zhou, "Ethnic disparities in the clustering of risk factors for cardiovascular disease among the Kazakh, Uygur, Mongolian and Han populations of Xinjiang: a cross-sectional study," BMC Public Health, vol. 12, no. 1, pp. 499-504, 2012.

[15] Y.-T. Wang, D. Adi, Z.-X. Yu et al., "The burden and correlates of hypertension among Chinese rural population in Han, Uygur, and Kazak: a cross-sectional study," Journal of the American Society of Hypertension, vol. 11, no. 11, pp. 737-745, 2017.

[16] C. M. Chen, W. H. Zhao, Z. X. Yang et al., "The role of dietary factors in chronic disease control in China," Zhonghua Liu Xing Bing Xue Za Zhi, vol. 27, no. 9, pp. 739-743, 2006.

[17] Z. Wang, Z. Chen, L. Zhang et al., "Status of hypertension in China," Circulation, vol. 137, no. 22, pp. 2344-2356, 2018.

[18] F. Dong, D. Wang, L. Pan et al., "Disparities in hypertension prevalence, awareness, treatment and control between Bouyei and Han: results from a bi-ethnic health survey in developing regions from South China," International Journal of Environmental Research and Public Health, vol. 13, no. 2, p. 233, 2016.

[19] X. Chen, L. Li, and T. Zhou, "Prevalence of hypertension in rural areas of China: a meta-analysis of published studies," PLoS One, vol. 9, no. 12, Article ID e115462, 2014.

[20] Ministry of Foreign Affairs of the People's Republic of China. Tajikistan country profile [EB/OL].https://www. fmprc.gov.cn/web/gjhdq_676201/gj_676203/yz_676205/ 1206_676908/1206x0_676910/.

[21] A. Aringazina, T. Kuandikov, and V. Arkhipov, "Burden of the cardiovascular diseases in central Asia," Central Asian Journal of Global Health, vol. 7, no. 1, p. 321, 2018.

[22] N. Aryal, M. Weatherall, Y. K. D. Bhatta, and S. Mann, "Blood pressure and hypertension in adults permanently living at high altitude: a systematic review and meta-analysis," High Altitude Medicine \& Biology, vol. 17, no. 3, pp. 185-193, 2016.

[23] L. Wang, M. Heizhati, D. Zhang et al., "Excess weight loss is a vital strategy for controlling hypertension among multiethnic population in northwest China: a cross-sectional analysis," Medicine (Baltimore), vol. 98, no. 36, Article ID e16894, 2019.

[24] L. S. Liu, "Writing group of Chinese guidelines for the management of hypertension, 2010 Chinese guidelines for the management of hypertension," Zhonghua Xin Xue Guan Bing Za Zhi, vol. 39, pp. 579-615, 2011.

[25] P. K. Whelton, R. M. Carey, W. S. Aronow et al., "2017 ACC/ AHA/AAPA/ABC/ACPM/AGS/APHA/ASH/ASPC/NMA/ PCNA guideline for the prevention, detection, evaluation, and management of high blood pressure in adults: A report of the American college of cardiology/american heart association task force on clinical practice guidelines," Hypertension, vol. 71, no. 6, pp. 13-115, 2018.

[26] The Central People's Government of the People's Republic of China, Decision of the Standing Committee of the National People's Congress Regarding the Amendment to the Individual Income Tax Law of the People's Republic of China, The Central People's Government of the People's Republic of China, Beijing, China, (In Chinese), 2011.

[27] C. M. Chen and L. Z. Kong, "For China Obesity Problem Working Group, "Chinese Adults Guidelines for the Prevention and Control of Overweight and Obesity", People's Medical Publishing House, Beijing, China, 2006.

[28] R.H. Hernández, H. Silva, M. Velasco et al., "Hypertension in seven Latin American cities: the cardiovascular risk factor multiple evaluation in Latin America (CARMELA) study," Journal of Hypertension, vol. 28, no. 1, pp. 24-34, 2010.

[29] X. Zhao, S. Li, S. Ba et al., "Prevalence, awareness, treatment, and control of hypertension among herdsmen living at 4,300 $\mathrm{m}$ in Tibet," American Journal of Hypertension, vol. 25, no. 5, pp. 583-589, 2012.

[30] T. Hasi, L. Hao, L. Yang, and X. L. Su, "Acetaldehyde dehydrogenase 2 SNP rs671 and susceptibility to essential hypertension in mongolians: a case control study," Genetics and Molecular Research, vol. 10, no. 1, pp. 537-543, 2011.

[31] M. L. Black, W. Wang, and A. H. Bittles, "A genome-based study of the muslim hui community and the han population of liaoning province, PR China," Human Biology, vol. 73, no. 6, pp. 801-81, 2001.

[32] L. Liu, L. Liu, Y. Ding et al., "Ethnic and environmental differences in various markers of dietary intake and blood pressure among Chinese Han and three other minority peoples of China: results from the WHO cardiovascular diseases and alimentary comparison (CARDIAC) study," Hypertension Research, vol. 24, no. 3, pp. 315-322, 2001.

[33] Uttarakhand Census http://www.census2020.co.in/census/ state/uttarakhand.html.

[34] N. Negi, R. Tamang, V. Pande et al., "The paternal ancestry of Uttarakhand does not imitate the classical caste system of India," Journal of Human Genetics, vol. 61, no. 2, pp. 167-172, 2016.

[35] Centers for Disease Control Prevention (CDC), "Racial/ethnic disparities in prevalence, treatment, and control of hypertension-United States," MMWR Morbidity and Mortality Weekly Report, vol. 54, pp. 7-9, 2005.

[36] O. Narvaez-Guerra, K. Herrera-Enriquez, J. Medina-Lezama, and J. A. Chirinos, "Systemic hypertension at high altitude," Hypertension, vol. 72, no. 3, pp. 567-578, 2018.

[37] L. Wang, N. Li, M. Heizhati et al., "Prevalence, awareness, treatment, and control and related factors of hypertension in multiethnic agriculture, stock-raising, and urban Xinjiang, northwest China: a cross-sectional screening for 47000 adults," International Journal of Hypertension, vol. 2019, pp. 1-8, 2019. 
[38] W. L. Chou and Z. Wang, "Regional inequality in China's healthcare expenditures," Health Economics, vol. 18, no. Suppl 2, pp. 137-146, 2009.

[39] R. Khatib, M. McKee, H. Shannon et al., "Availability and affordability of cardiovascular disease medicines and their effect on use in high-income, middle-income, and low-income countries: an analysis of the pure study data," The Lancet, vol. 387, no. 10013, pp. 61-69, 2016.

[40] Z. Wang, X. Wang, Z. Chen et al., "Hypertension control in community health centers across China: analysis of antihypertensive drug treatment patterns," American Journal of Hypertension, vol. 27, no. 2, pp. 252-259, 2013.

[41] G. Parati, G. Bilo, A. Faini et al., "Changes in $24 \mathrm{~h}$ ambulatory blood pressure and effects of angiotensin II receptor blockade during acute and prolonged high-altitude exposure: a randomized clinical trial," European Heart Journal, vol. 35, no. 44, pp. 3113-3122, 2014.

[42] V. G. DeMarco, A. R. Aroor, and J. R. Sowers, "The pathophysiology of hypertension in patients with obesity," Nature Reviews Endocrinology, vol. 10, no. 6, pp. 364-376, 2014. 